\title{
Robotics and Education: A Systematic Review
}

\author{
Itsaso Arocena, Asier Huegun-Burgos, Itziar Rekalde-Rodriguez \\ University of the Basque Country, HEFA I faculty, Didactics and School Organization department, \\ San-Sebastian, Spain
}

\begin{abstract}
Digital society is here, and it came to stay. One of our daily lives where information and communication technologies have the most significant impact is education. This systematic review analyzes the presence that technology, robotics specifically, has had on our educational system in recent years. Some keywords have been chosen, and screening has been carried out in the three most extensive databases about didactic and education: Education Resources Information Center, Scopus, and Web of Science chosen for being the most relevant in education sciences. Although among the most remarkable results, it was found that robotics is used as an individual skill developing tool. Its benefits as a teamwork promoting tool are not yet widely applied.
\end{abstract}

Keywords - robotics, education, school, didactic intervention, inclusion, bibliometric review.

\section{Introduction}

The world is going through a digital transformation. The way we access information changes, allowing us to acquire knowledge and generate information, the essential elements in this transformation [13]. This integration of Information and Communication Technology (ICT) has transformed the world forever.

DOI: $10.18421 /$ TEM111-48

https://doi.org/10.18421/TEM111-48

Corresponding author: Itsaso Arocena, University of the Basque Country, HEFA I faculty,

Didactics and School Organization department,

San-Sebastian, Spain.

Email: itsaso.arocena@eu.eus

Received: 10 January 2022.

Revised: 14 February 2022.

Accepted: 19 February 2022.

Published: 28 February 2022.

(c) BY-NC-ND (C) 2022 Itsaso Arocena, Asier Huegun-Burgos \& Itziar Rekalde-Rodriguez; published by UIKTEN. This work is licensed under the Creative Commons AttributionNonCommercial-NoDerivs 4.0 License.

The article is published with Open Access at https://www.temjournal.com/
As a result, new cultural practices have emerged, different forms to relate, new problems, social inequalities, cultural gaps, and economic factors that we must face as professional educators [3].

Far from considering the technologies as a miracle that will solve all the problems of education, we should conceive them as a window of opportunity [13], a window that will take us to a pedagogical and social renewal [18].

Having basic ICT knowledge means accessing, managing, integrating, evaluating, and creating information easily using technologies and digital communication. Therefore, the progression in digital literacy is necessary from an educational point of view [24].

\section{a. ICT and Education}

Diverse research proves that using the ICT in the classroom improves the learning experience [24], [22]. Students enjoy using ICT over the master class teaching methodology since it gives more dynamism to the lessons, making them more attractive and participative. In addition, it makes learning more cooperative, leaving aside mechanical and memory learning to focus on more challenging and complex projects by using an interdisciplinary approach.

The research methods have evolved from the first introduction of ICT in schools till nowadays [26]. The education community has gone from being concerned about individual learning with computers in concrete learning situations to using experimental methodologies towards more longitudinal studies with qualitative techniques to study cases in authentic teaching contexts [23].

The first studies made in the sixties and seventies regarded the distribution and uses of computers in schools and the results obtained by the students when they worked with these machines [6]. The main interest was in measuring whether computers were more efficient than other performance means. However, in the mid-eighties, the situation changed rapidly with the arrival of innovative electronic materials [4], [23]. Then, it was commonly accepted that the effects of technologies on teaching and learning could be understood if analyzed as part of a multiple factor interaction in the complex context of the school [1]. 
Even though technological resource availability increases in schools, such as computers, broadband Internet connection, whiteboards, or digital projectors, the presence and pedagogical use of the ICT has not yet become the widespread or integrated practice in schools resources in education is still low. Many teaching practices do not represent progress, innovation, or improvement over traditional practices. Teachers use the ICT to support existing pedagogies without representing a substantive alteration of the principles and methods of teaching [15]. Technology provides possibilities for implementing various learning activities in the classroom [19]; we educators are responsible for using these tools.

Even today, technology occupies a specific space in the classroom, primarily dedicated to learning these technologies, that is, to developing students' digital competence. However, its presence is not yet natural and extended to all subjects.

\section{b. Robots as ICT tools}

Before talking about robots as ICT tools, we should specify what we mean by robots. Robots as a concept differ among scientists, but mostly all agree on certain factors. Thus, a robot is a programmable machine that can manipulate objects and perform operations that only humans could previously perform. In addition, robots provide a capacity, thought, or resolution feeling, although they are mostly limited to executing orders [14].

Educational robotics is part of the area of robotics we call social robotics. Social robotics is growing within human society, developing a significant presence in our daily lives. We gradually include robots in human social life [30]. However, what do we mean when we say that a robot is social? Sociability implies the existence of interaction relationships. A social robot is an agent that can interact and have communicative behavior [10].

The first social robotics experiences occurred between the 40s and 90s. They were aimed at the area of biology and the animal world. The first attempts at social robotics tried to integrate a robot in a species' natural context and create communication between them in this context in order to obtain more information about the said species [7], [14], [25]. Then, from the 90 s to about 2010, the first robot designs aimed at interacting with humans began to appear.

These early human-directed interventions were mainly designed from a therapeutic point of view. The robot tries to fill a lack or cure a specific disease or behavior. Robotics and psychology converge in this type of therapeutic intervention, were usually carried out in a laboratory context, with one robot, one to five participants, and several researchers observing the scene [2].
Much progress has been made since those first social robots. The technology currently available for researchers far exceeds what the pioneers of robotics had. In the last decade, we are experiencing the rise of educational robotics [25]. More and more brands are producing commercial robots aimed at education. In recent years, the educational community has determined that robotics in school should occur within the classroom, be inclusive with all students, and collaborate with teachers. Although most educational interventions still do not fulfil these characteristics, we approach this goal [8], [25].

Robotics is part of the ICT tools, key learning in a world where children interact with multiple technologies and operating systems throughout their lives. Students build and program robots during robotics lessons and develop computational, engineering, logical-mathematical thinking, problem-solving, and scientific inquiry. In addition to this, the tangibility of robotic platforms is a deciding factor to improve students' motivation since it allows a better immersion in the learning process [17].

Besides those traditionally linked to technology, robotic platforms have also proved effective for interdisciplinary knowledge learning and improving different skills, such as; creativity, collaboration, communication, or autonomy [12]. Thus, on the one hand, they are beneficial for students studying different stages of the educational process, and on the other hand, for students with specific needs for educational support [29], [27].

So, educational robotics must become part of the landscape of teaching tools and methodologies in schools, becoming a key element in the union and articulation of interdisciplinary learning [9].

\section{Aims and Goals}

This review is the initial stage of a more extensive research project called IkasBot. This project collaborates between the University of the Basque country and the Support Center for Training and Educational Innovation in the province of Gipuzkoa. The project's objective is to develop joint attention in students with autism spectrum disorders, working at school within the ordinary classroom.

IkasBot is a didactic program composed of three blocks, with four sessions each, throughout the school year, and uses a robot as a tool. The project has the University of the Basque Country ethics committee certificate and is already being applied in schools in the Basque country.

In order to design IkasBot, similar projects applied previously in various universities, and research centers around the world have been taken into account. Furthermore, three systematic reviews have 
been carried out, this being one of them. These questions have led us to develop this systematic review:

- What type of interventions carried out with robots does the literature collect?

- At what school age have these studies been carried out?

- What do these interventions aim to do?

- Are these aims related to the students participating?

- What is the profile of these participants?

\section{Method}

This work is descriptive, whose objective is to identify the state of the art of social robotics in the school and educational setting. To do so, the educational interventions published on this topic in recent years have been reviewed. Educational intervention is a specific program designed to help children with their learning difficulties. They are arranged so that students can be evaluated in order to measure their progress. Research and intervention do not exist separately; they are complementary. It is not possible to develop educational research without the intervention and transformation of the educational context; much less perform an intervention without first investigating [5].

This revision allows us to create a mental image of the current situation of this issue in the scientific community.

\section{a. Type of Study}

In order to achieve these aims, the most appropriate method is to develop a bibliometric review. Bibliometric reviews are helpful to describe and understand the activity carried out by education professionals in different research centers and universities around the world. Besides, it allows us to collect a sample of the interventions that are being carried out in education that use robots as a tool and to compare the different techniques used, as well as the data collection methodologies, evaluation of the students, and analysis of the information obtained [16]. Moreover, this system allows us to capture a realistic image of the work done in this area in recent years, which we consider necessary to analyze and understand before designing our educational intervention.

In order to carry out the said bibliometric review, we researched through the three most relevant databases in the field of education: Web Of Science (WOS), Education Resources Information Center
(ERIC) and Scopus. Why these three databases? Firstly because of their demonstrated quality criteria, secondly due to their broad reach and impact, and thirdly because they function internationally.

Web of Science is an online scientific information service, provided by Clarivate Analytics, integrated into ISI Web of Knowledge. Scopus is a bibliographic reference and citation database that belongs to Elsevier company and provides peerreviewed literature and quality web content, as long as monitoring, analysis, and visualization tools. Finally, ERIC is the essential education specialized database available online. It was funded by the Institute of Education Sciences of the United States Department of Education.

This method is systematic and reproducible and facilitates us to evaluate and synthesize the whole academic work existing about this topic, registered by researchers [11].

\section{b. Procedure}

This process's starting point was to identify the literature to be included in the sample [21]. The keywords entered were: robotics, education, intervention and school, joined by the boolean AND, and the words therapy and review, with the boolean NOT. No publication years were used in the screening process. The selection of words responds to the objective of this systematic review, which is to analyze what interventions have been carried out in the field of education using socio-educational robotics, always from a didactical and not a therapeutical point of view.

Didactics is the science of teaching or creating scenarios and challenges where students can learn. Describes, explains and establishes the most appropriate and effective methods to lead the student to the progressive acquisition of habits, techniques and comprehensive training [28]. Since our aim is educational, we only analyzed interventions with teaching objectives, and we discarded those that aimed to diagnose or cure various disorders.

\section{c. Sample}

When the keywords mentioned earlier and their corresponding booleans were introduced in the databases, 105 papers were obtained; 35 in WOS, 21 in ERIC and 49 in Scopus. The next step was to delete all the repeated papers and manually discard those unrelated to the educational area [20]. This process left us with the final amount of 66 papers to review (Figure 1). This research took place in June of 2020. 


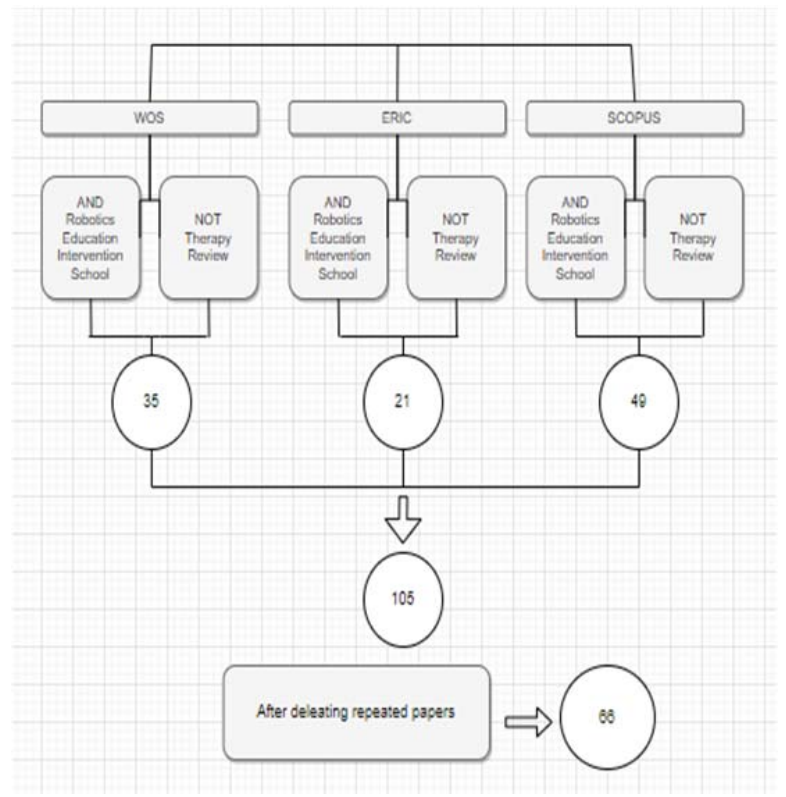

Figure 1. Research process visualization

Finally, the analysis of the selected papers was carried out. When analyzing the sample obtained, we took into account the following indicators:

- Publication year

- Publication country

- The intervention was carried out in the ordinary classroom or outside the school environment

- The teachers were involved in the intervention or not

- The objective of the intervention was didactic/educational or not

- Which was the robot model used in the intervention

- The intervention obtained a positive or negative output

- The intervention was related to any scholarly subject or not

- Which scholar stage was the intervention applied in (age of the students)

- Which was the research method used to analyze the results of the intervention

We selected this indicator to approach state-of-theart and create a realistic picture of the real presence of robotics in the school [21].

\section{Results}

The results are articulated following the goals mentioned before. Figure 2. visualizes all the articles organized by their publication years and the number of published articles each year. The first one was published in 2000 and the last one in 2020.

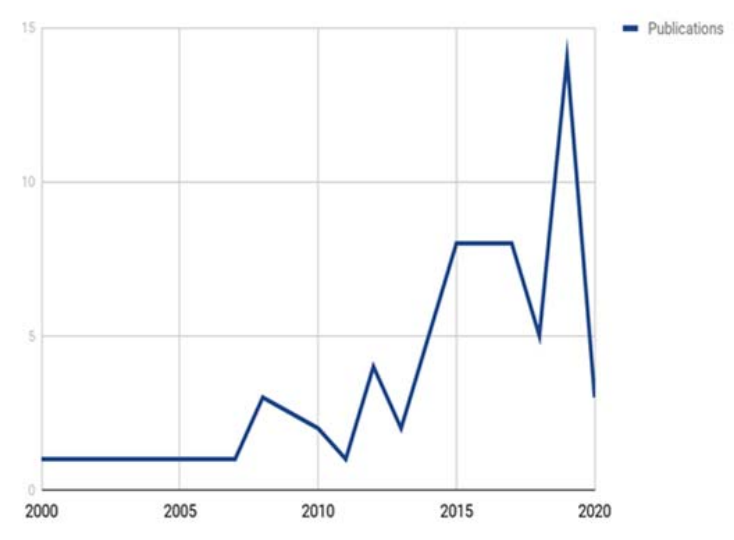

Figure 2. Publication years

The publication amount has constantly increased every year. For example, eight articles were published between 2000 and 2010, and 41 articles were published between 2011 and 2018 until reaching their maximum peak in 2019 with 14 published articles. However, 2020 has just started this year, so this figure will likely be maintained or even outnumbered.

Next, the countries where these educational interventions took place were analyzed. North America is the country where this topic has been more researched, with 33 interventions carried out.

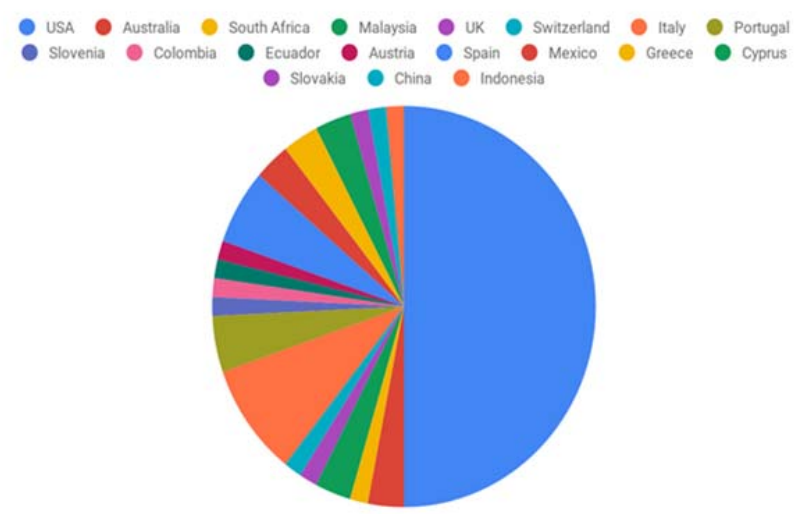

Figure 3. Countries

We find Italy in the second place, with six interventions, closely followed by Spain, with four interventions and Portugal with 3 of them. Finally, Australia, Malaysia, Mexico, Greece and Cyprus carried out two interventions. South Africa, UK, Switzerland, Slovenia, Colombia, Ecuador, Austria, Slovakia, China and Indonesia carried out one educational intervention on their territory.

After the application country, the didactic environment of these interventions was analyzed if the interventions took place in the ordinary schools and classrooms where the participants study or not. Also, if their teachers were involved in the interventions in any way. 


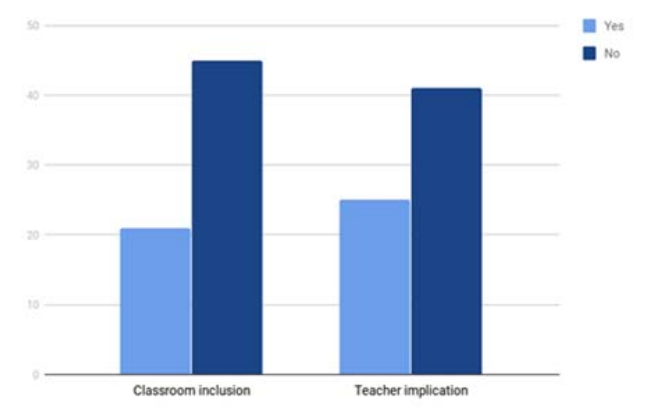

Figure 4. Classroom inclusion and teacher implication

Figure 4. shows that most of the interventions were executed out of the educational system. Indeed, many of them were organized as summer camps, and some were planned as extra-school activities. However, only 21 of the 66 interventions took place at school, including all the students in the classroom.

However, when looking at the teacher implication, the figures do not fit since the number of interventions involving school teachers is higher than the number of interventions carried out at the school itself. Although not carried out in the school system, some of the research did include teachers to train them and carry out these dynamics in their classrooms in the future.

Following classroom inclusion and teacher implication, the objectives of these interventions were analyzed. As educators, our interest lies in whether these objectives are didactic. They try to teach something to their students or respond to other needs, not specifically educational.

From the total amount of 66 interventions that were analyzed, a great quantity had didactic objectives. Indeed, only 17 articles had non-didactic objectives. Among these non-didactic objectives, the most repeated (Figure 5), with six publications, made students interested in science, technology, engineering and mathematics (STEM) related degrees. Secondly, with five publications, we find those interventions that aim to evaluate a program or a robot and reduce the gender gap, getting female students interested in STEM degrees. Finally, only one of the interventions aims to prevent early school leaving.

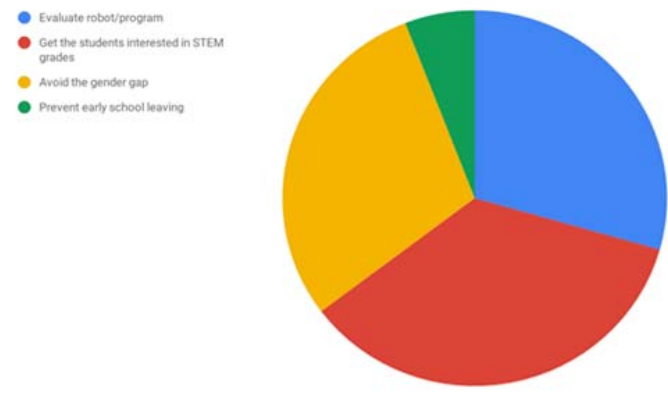

Figure 5. Non-didactic objectives
Continuing with those interventions with didactic objectives (Figure 6.), we can observe that the most repeated objective is to teach programming to students with 17 publications in this regard. Closely followed, with ten publications each, those aiming to teach STEM subjects and those aiming to teach communicative skills. Fourth, with five publications, we have those interventions that try to develop the digital competence of their students. Finally, with less than three publications for each of them, we find interventions that aim to teach astronomy, work all subjects through technology, teach law, teach nutrition and teach art.

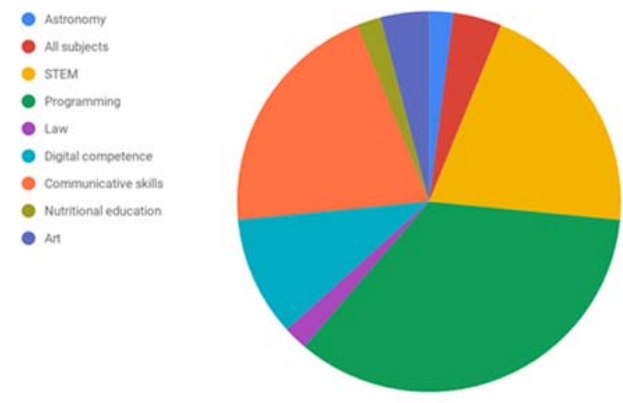

Figure 6. Didactic objectives

Once the objectives of the interventions were analyzed, the fulfillment of these objectives was checked to determine if socio-educative robotics is an appropriate tool in education.

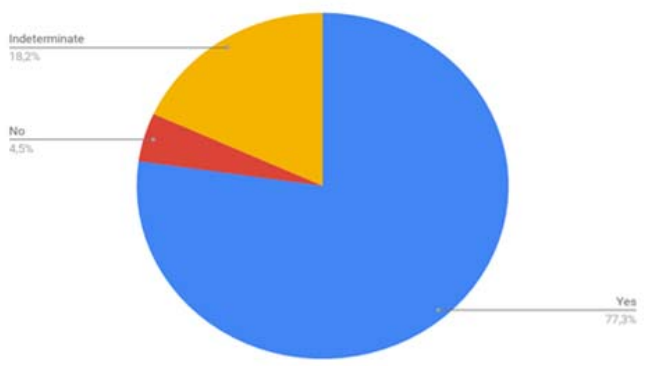

Figure 7. Positive output

Most of the interventions, 51 precisely, fulfilled their objectives, three did not achieve what they expected, and 12 remain indeterminate since they are proposals yet to be applied (Figure 7). Following, the robot models used in the interventions were analyzed.

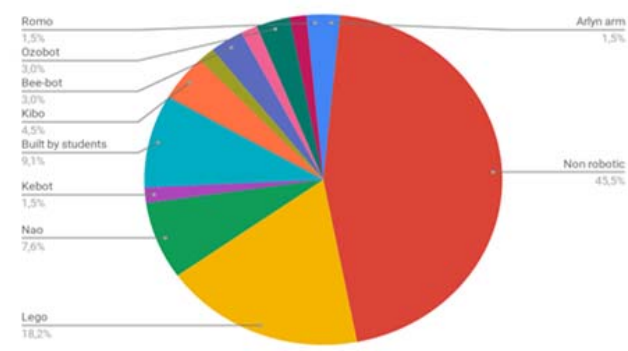

Figure 8. Robot model 
Starting with an unexpected fact, most of the interventions analyzed in this review, exactly 30 publications, did not use a robot but a computer program to work on robotics. As we can see in Figure 8., the rest of the interventions used robots, the most used being Lego, with 12 references, followed by Nao in the second place, with five references, and finally, to a lesser extent, other commercial models such as; Kibo, with three references, Bee-Bot and Ozobot, with two references each. Finally, Arlyn, Kebot, Dash, Thymio, Mbot and Romo, with one reference each. It should be noted that 6 of the analyzed publications chose to build their robot, along with the students.

Next, these interventions and their relation to the subjects learned at school were analyzed. Not the objectives, didactic or not, of these interventions, but their relationship with the subjects worked on at school. Considering that these interventions are aimed at students in different phases of the scholar system, we wanted to see if the proposals were aimed at working on the content studied in the classroom by using robotics or focusing on topics outside the school context.

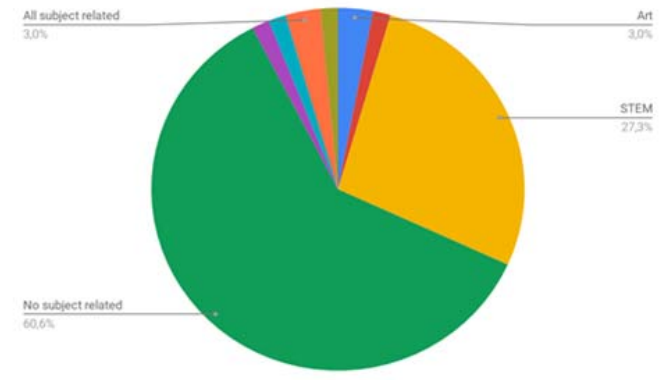

Figure 9. Subject related

Figure 9. shows that most of the interventions, even those with didactic objectives, were not related to the subjects taught to the participants at school, 40 of them. First, regarding the interventions that aim to improve classroom teaching methodologies, we found those interventions aimed at learning STEM subjects; 18 of them. Secondly, with a much lower number of publications, we found the rest of the interventions related to art, one related to astronomy, one related to law, one related to history, and one related to digital competence. Finally, two of the articles proposed robotics to work all of the subjects transversally.

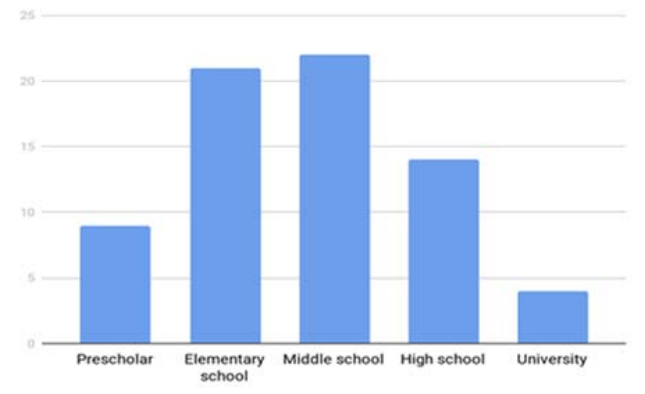

Figure 10. School stage
Next, the school stage in which the analyzed interventions have been carried out was determined. As we can see (Figure 10.), most interventions were applied in the elementary school, with 21 publications, and middle school stages, with 22 publications, followed by the high school stage, with 14 publications, the preschool stage, nine publications and the university stage with four publications.

Considering that these interventions were developed in different countries, the scholar stages referred to in the articles are different. We used the United States school system as a reference since most of the interventions have been carried out there. Preschool education goes from ages 3-5 years old. Elementary school goes 5-10 years old; middle school is $10-14$ years old; high school is $14-18$ years old and higher education from 18.

Nevertheless, some of the interventions were proposed to be applied throughout the whole school stage. It should be noted that $18.2 \%$ of the interventions were designed for students of different ages with specific learning disorders, such as; Autism Spectrum Disorders, Down Syndrome, or gifted students. In the case of these students, the school stage in which they were enrolled was not specified, and groups were organized with students of different ages.

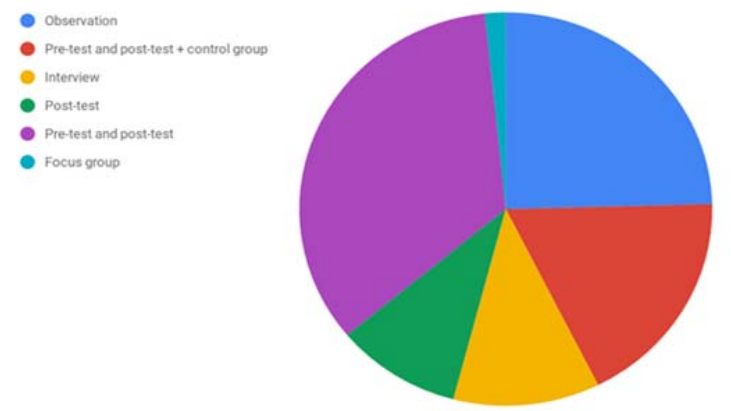

Figure 11. Method

Finally, the research methods used in the educational interventions included in this review were collected:

1. As we can see in Figure 11, the most widely used system is the pre-test and post-test, with 32 publications, 11 of which, in addition to using pre-test and post-test, also used a control group to compare the results.

2. We have systematic observation with 15 publications. We find the interview with seven publications in the fourth place, fifthly the posttest system with six publications.

3. The teachers focus group, with a single publication where it has been used as a research method. 


\section{Discussion}

A clear positive progression can be seen in this topic; robotics has a growing presence in the school. As each year goes by, more research is carried out, and more articles are published. When a topic undergoes such growth, it can be deduced that there is an acceptance by the scientific community, and the results being obtained are hopeful and promising [6].

As for the countries where this topic is most investigated, the United States indisputably occupies the first position. This presence may also be since we have found more articles published there than in other countries. One of the databases we have searched is ERIC, which belongs to the United States government ministry of education. In the second place, we find Italy, which has surprised us. We expected to find countries with more parallel development and resources similar to the United States, such as Australia or Canada. Unfortunately, the literature does not offer us a justification for this issue, but looking ahead, it can be an exciting research thread.

It is commonly accepted that introducing the ICT in the classroom makes the educational process a more engaging experience for students, fosters cooperative learning and improves the overall educational experience [24], [17]. This premise can be applied to the whole stages of school education and all of the subjects [13]. However, given the results of this review, we see that most interventions carried out using robots aimed to learn about robotics or programming instead of the subjects developed at school. Furthermore, these interventions have been aimed at students who are in the elementary school, middle school, and high school stages for the most part. Only in a few cases have we found interventions aimed at the preschool and university stages.

In addition to this, scientific literature shows us that robotics can be a great ally of the teacher in the classroom [22], although almost all of the interventions reviewed were carried out outside the classroom and rarely incorporate teachers. The researcher is usually an external agent, who implements an intervention in an extracurricular way, and then leaves. There is no continuity of the academic content worked at school. However, many of the interventions mention this as a future goal. Although today, few robotic interventions are carried out within the classroom and with the collaboration of teachers, this seems to be the way forward in the future.

The educational, scientific community commonly accepts that learning is a group activity [28]. Therefore, we build our knowledge in a specific social context. In this case, this scenario is the school. On the other hand, when the ICT was first introduced in classrooms, the research community focused more on individual learning and improvement [6]. However, today we know that this learning process takes place in the actual social context, and thus all the pieces that complete the puzzle of this context are analyzed, such as teachers, families, students, or space itself [23].

Contrary to what theory probes in didactics and educational sciences, in this systematic review, in terms of social robotics in the classroom, the most widely used research method is that of pre-test and post-test. This method collects the student's progress without considering the social context in which said progress takes place. Nevertheless, unfortunately, systematic observation is also prevalent as a research method. Only a few interventions did the researchers decide to interview the teaching staff and thus receive their views and experience. This is a contradiction that will have to be resolved in the future in order to obtain reliable data.

Finally, we have found a strong inclination in using robotics towards students with specific needs for educational support. This data is consistent since robotics has proven to be very effective in students with special needs [12].

\section{Conclusion}

In the last two decades, publications on socioeducational robotics have been increasing in the area of education. Therefore, it can be said that the scientific community sees the potential of robots as educational tools and validates their use for educational purposes.

Analyzing the educational interventions included in this review, very few are carried out within the classroom, while most are proposed as extra scholar activities. Many of the interventions aimed to get it applied in the school in the future. There can be seen, therefore, a cautious but constant approach of robotics towards school.

Regarding the objectives of the reviewed interventions, it was seen that most used robotics to try to teach programming to students. When focusing on interventions that aimed to improve a subject, most of them focused on those subjects called the STEM; science, technology, engineering and mathematics. A few interventions dared to use robotics to work on other subjects, although the results are auspicious.

Regarding the most used commercial or noncommercial robot models in these educational interventions, a noticeable fact was found: most of the interventions did not use a physical robot, but a program for a computer or a tablet device, where the students could practice programming. This decision is understandable since commercial robot models are not easy to obtain due to their price and need for maintenance. 
Regarding the teachers' involvement, it can be seen that there are few interventions where the school teachers actively participate. However, the educational researchers' community wants robotics to enter schools and classrooms, so teachers must be included in the design of the interventions to know their needs and during the evaluation of those interventions. This implication includes training teachers on socio-educational robotics. If they do not want these interventions to remain anecdotal or punctual, school teachers must see what robotics can contribute to the classroom and introduce them into their students' day-to-day lives.

Ultimately, it should be noted that $18.2 \%$ of these interventions were designed to work with children with specific educational support needs.

\section{References}

[1]. Segura, J. A., \& Quintero, L. J. C. (2012). Tecnologías emergentes, $i$ pedagogías emergentes?. In Tendencias emergentes en educación con TIC (pp. 13-33). Espiral.

[2]. Arocena, I., Rekalde-Rodriguez, I \& Graña, M. (2018). Social robots for children with autism spectrum conditions: A review of some selected studies. Zenodo. http://doi.org/10.5281/zenodo.1493664

[3]. Barker, B. S., \& Ansorge, J. (2007). Robotics as means to increase achievement scores in an informal learning environment. Journal of research on technology in education, 39(3), 229-243.

[4]. Barrios, J., Kang, R., Morel, S., Kang, D., López, A., \& Martínez Jara, E. A. (2015). Inclusión Tecnológica de Niños mediante Robótica Educativa de bajo costo. In $X$ Congreso sobre Tecnología en Educación \& Educación en Tecnología (TE \& ET)(Corrientes, 2015).

[5]. Burgo Bencomo, O. B., León González, J. L., Cáceres Mesa, M. L., Pérez Maya, C. J., \& Espinoza Freire, E. E. (2019). Algunas reflexiones sobre investigación e intervención educativa. Revista Cubana de Medicina Militar, 48

[6]. Cesar, C. (2018). Psicologia de la Educacion Virtual. Ediciones Morata.

[7]. Chevalier, M., Riedo, F., \& Mondada, F. (2016). Pedagogical uses of thymio II: How do teachers perceive educational robots in formal education?. IEEE Robotics \& Automation Magazine, 23(2), 16-23.

[8]. Conchinha, C., Silva, S. G., \& Freitas, J. C. (2015). La robótica educativa en contexto inclusivo. Ubicuo social: Aprendizage con TIC.

[9]. Conchinha, C., Osório, P., \& de Freitas, J. C. (2015, November). Playful learning: Educational robotics applied to students with learning disabilities. In 2015 International symposium on computers in education (SIIE) (pp. 167-171). IEEE.

[10]. Damaševičius, R., Maskeliūnas, R., \& Blažauskas, T. (2018). Faster pedagogical framework for steam education based on educational robotics. International Journal of Engineering and Technology, 7(2.28), 138142.
[11]. Díaz-Posada, L. E., Varela-Londoño, S. P., \& Rodríguez-Burgos, L. P. (2017). Inteligencias múltiples e implementación del currículo: avances, tendencias y oportunidades. Revista de Psicodidáctica, 22(1), 69-83.

[12]. Domínguez, A., \& Stipcich, M. S. (2018). Trabajo colaborativo y TIC para ayudar a un estudiante con $\mathrm{TDA}^{*}$ a aprender física. Revista de enseñanza de la física, 30(1), 53-61.

[13]. Escobar, J. F. G., \& Mira, Y. M. O. (2019). La globalización y la importancia de las TIC en el desarrollo social. Revista Reflexiones y Saberes, (11), 2-9.

[14]. Falah, B., \& Noreddine, H. (2017). Pedagogical Robotics-A Way to Experiment and Innovate in Educational Teaching in Morocco. International Journal of Education and Learning Systems, 2.

[15]. García-Valcárcel Muñoz-Repiso, A., Casillas Martín, S., \& Basilotta Gómez-Pablos, V. (2020). Validation of an Indicator Model (INCODIES) for Assessing Student Digital Competence in Basic Education. Journal of New Approaches in Educational Research, 9(1), 110-125.

[16]. Hallinger, P., \& Kovačević, J. (2019). A bibliometric review of research on educational administration: Science mapping the literature, 1960 to 2018. Review of Educational Research, 89(3), 335-369.

[17]. Jurado Cojo, E., Fonseca Escudero, D., \& Canaleta Llampallas, X. (2019, October). Acompañamiento a profesores de Infantil para integrar la robótica en el aula: experiencia realizada en cuatro escuelas en Cataluña. V Congreso Internacional sobre Aprendizaje, Innovación y Cooperación. CINAIC 2019.

[18]. Kazakoff, E., \& Bers, M. (2012). Programming in a robotics context in the kindergarten classroom: The impact on sequencing skills. Journal of Educational Multimedia and Hypermedia, 21(4), 371-391.

[19]. Kubilinskienè, S., Žilinskienè, I., Dagienė, V., \& Sinkevičius, V. (2017). Applying robotics in school education: A systematic review. Baltic journal of modern computing, 5(1), 50-69.

[20]. Kunisch, S., Menz, M., Bartunek, J. M., Cardinal, L. B., \& Denyer, D. (2018). Feature topic at organizational research methods: how to conduct rigorous and impactful literature reviews?. Organizational Research Methods, 21(3), 519-523.

[21]. Linnenluecke, M. K., Marrone, M., \& Singh, A. K. (2020). Conducting systematic literature reviews and bibliometric analyses. Australian Journal of Management, 45(2), 175-194.

[22]. Marti, J. A., Heydrich, M., Rojas, M., \& Hernández, A. (2010). Aprendizaje basado en proyectos: una experiencia de innovación docente. Revista Universidad EAFIT, 46(158), 11-21.

[23]. Area Moreira, M., Hernández Rivero, V., \& SosaAlonso, J. J. (2016). Modelos de integración didáctica de las TIC en el aula $=$ Models of educational integration of ICTs in the classroom. Modelos de integración didáctica de las TIC en el aula= Models of educational integration of ICTs in the classroom, 79-87. 
[24]. Rodríguez Pérez, R. A., \& Gómez Pérez, C. (2014). La enseñanza de la Guerra Civil en Bachillerato. Una experiencia educativa apoyada en el uso de las TIC. Pagès, J. y Santisteban Fernández, A.(coords.). Una mirada al pasado y un proyecto de futuro. Investigacóón e innovación en didáctica de las ciencias sociales, I (449-450). Barcelona: UAB.

[25]. Santos, I., Grebogy, E. C., \& Medeiros, L. F. D. (2019). Crab robot: a comparative study regarding the use of robotics in STEM education. In Smart Learning with Educational Robotics (pp. 183-198). Springer, Cham.

[26]. Šiaulys, T. (2021, June). Developing Interactive Visualizations Focusing on Computational Thinking in K-12 Computer Science Education. In Proceedings of the 26th ACM Conference on Innovation and Technology in Computer Science Education V. 2 (pp. 680-681).
[27]. Taylor, M. S., Vasquez, E., \& Donehower, C. (2017). Computer programming with early elementary students with Down syndrome. Journal of Special Education Technology, 32(3), 149-159.

[28]. Urban, M., Murauyova, H., \& Gadzaova, S. (2017). Didactic principles of visualization of mathematical concepts in primary education. Pedagogika, 127(3), 70-86.

[29]. Wright, J. C. (2019). Video Prompting to Teach Robotics and Coding to Students with Autism Spectrum Disorder. Vanderbilt University.

[30]. Yanış, H., \& Yürük, N. (2020). Development, validity, and reliability of an educational robotics based technological pedagogical content knowledge self-efficacy scale. Journal of Research on Technology in Education, 53(4), 375-403. 